\title{
Flavia Buzzetta, Magia naturalis e scientia cabalae in Giovanni Pico de la Mirandola. Studi pichiani 20, Firenze, Leo S. Olschki, 2019, x-344 pp., ISBN: 9788822266309. Cloth €35
}

\author{
Reseñado por CARLOS ORTIZ DE LANDÁZURI \\ Universidad de Navarra, Pamplona, ES \\ cortiz@unav.es
}

Flavia Buzzetta, investigadora de los Altos Estudios de la universidad de Paris, se ha especializado en las relaciones entre cristianismo y judaísmo en la época renacentista, dedicando una especial atención al abigarrado pensamiento de Pico de la Mirándola (1463-1494). Se trata de dirimir hasta qué punto la tradición judío-cristiana fue capaz de aportar una visión verdaderamente original de los problemas filosóficos, habiendo dos posibles actitudes a ese respecto: o bien se sigue la forma hebrea de abordar este problema, considerando que la Tora o ley escrita ya está definitivamente revelada, sin que la razón humana pueda hacer nada por prolongarla ni conseguir descifrar los secretos acerca de la divinidad que encierra. O bien adoptar una actitud cristiana que considera que las verdades reveladas por la Torá o ley escrita están abiertas a posteriores desarrollo que pueden ser conocidos a través de la propia revelación o con ayuda de la razón discursiva.

Según Buzzetta, Pico en la trilogía de su periodo romano de juventud (1483-1489), especialmente en la Oratio de hominibus dignitates, en la Apología y en las Conclusiones, así como en el Hepptaplus, habría tratado de justificar una posible articulación entre las verdades reveladas del cristianismo, su teoría filosófica acerca de la magia y la actividad práctica secretista desplegada por la cábala, sin atribuirles un mensaje cerrado a posteriores desarrollos sapienciales. Sin duda se trata de una empresa llena de dificultades debido no sólo al secretismo de las propuestas hebreas, sino al modo hermético y asistemático como Pico expresa su propio pensamiento. De todos modos el propósito de la autora es comprobar cómo las tesis defendidas en su periodo de juventud configuran un proyecto programático totalmente coherente, dando unidad a un mosaico de propuestas netamente cristianas que no están aisladas del resto de su evolución intelectual. En este contexto la cábala representaría para Pico la multiplicidad y diversidad de las posteriores aplicaciones prácticas de su previa filosofía de la magia, mostrando a su vez cómo ambas están intrínsecamente relacionadas entre sí y son susceptibles de un posterior desarrollo cristiano donde pueda seguir teniendo cabida la reflexión noción mutuamente compartida acerca de las condiciones de posibilidad de un cosmos creado por Dios.

Pero a pesar de discrepar respecto del secretismo de la cábala judía, Pico sigue manteniendo unos límites respecto del posterior desarrollo de las verdades divinas. En su opinión, se debe establecer una estricta separación entre la magia natural lícita que también podría ser practicada por el cristianismo, y la magia demoniaca o ilícita, que 
justifica la existencia de fuerzas ocultas perversas o benévolas, cuyo ejercicio está reservado a la intervención de entidades espirituales, y que no está regulada por la moral cristiana o judía, salvo el mandato explícito de la divinidad. En este contexto Pico concibe la magia lícita como una ciencia o saber conceptual que está siempre abierta a posteriores de- $\quad$ sarrollos, ya opere según un modelo aristotélico o neoplatónico, siempre que se mantenga dentro de los límites establecidos por la omnipotencia divina. En cambio la magia demoniaca ilícita persigue introducir el desorden en el orden creado de la naturaleza, sin respetar los fines que persigue la ley moral y física establecida por la omnipotencia divina. En efecto, en la medida que se establece una simpatía natural entre todos los elementos de la naturaleza, los seres naturales configuran una estructura orgánica que puede ser objeto de una ciencia universal enciclopédica y que puede desarrollarse y ponerse al servicio del orden creado, pero que no se puede violar sin introducir el mal en el comportamiento de la naturaleza.

De este modo la magia vista desde una perspectiva teológico-religiosa cristiana, no sólo es filosofía sino el absoluto cumplimiento de los designios dados por Dios respecto de la filosofía natural. Solo cuando el hombre ejerce de «mago» puede interactuar con el reino que a su vez Dios ha querido darle como herencia. Por su parte, el hombre puede ejercer como mago en cuanto actúa como ministro de la naturaleza, en la medida que se subordina en todo momento a los designios del Creador y trata de darle la mayor gloria posible. En este sentido la magia se concibe dentro de un proceso de elevación del hombre hacia la divinidad, que conlleva a su vez una absoluta transformación moral, sapiencial y espiritual. Pero de igual modo permite configurarse de un modo camaleónico cómo el auténtico protagonista de una posible «re-invención» de la totalidad del universo físico dado su potencial conocimiento enciclopédico del conjunto de las ciencias, tanto teóricas como prácticas.

Esta articulación entre la magia y la cábala se presta a muchas malinterpretaciones, salvo que se preste a cada término el sentido exactos hora indicado. De hecho se le habría acusado a Pico de haber puesto en ejercicio, junto a Marsilio Ficino, prácticas rituales ligadas a la «magia natural» y a la doctrina «cabalística», con la pretensión de hacer milagros y acciones proféticas totalmente infundadas. Sin embargo Flavia Buzzetta trata de mostrar cómo este tipo de comportamientos, si son correctamente interpretados, pueden resultar totalmente legítimos. Eso sí, habría que establecer una estricta separación entre la parte práctica de la ciencia de la cábala respecto de la parte teórico-doctrinal de la cábala especulativa, que puede legitimarse si se lleva a cabo una profundización y clarificación sobre el tema, pero que fácilmente puede resultar más polémica.

Buzzeta aborda así lo que ahora se concibe como una de las mayores aportaciones del pensamiento de Pico, a pesar de que Pico no la habría abordado desde un punto de vista sistemático teórico ni en su aspecto práctico. Es decir, si se concibe la cábala como una reformulación hermenéutica en clave cristiana de las condiciones de posibilidad de la creación del universo físico, entonces la cábala deja abiertas una pluralidad de vías filosóficas que conducen a una única verdad. De ahí que la cábala cristiana se presente 
como una disciplina sapiencial «totalizante» mediante la que se pretende aportar una «regulación» acerca de los requisitos que debe cumplir lo cognoscible por el hombre. Se lleva a cabo así una transformación de una qabbalah hebrea en una cábala cristiana donde además de acogerse todos los principios revelados de la ley mosaíca, se recogen también todos los posteriores desarrollos de las verdades reveladas por parte de la fe cristiana y de las verdades descubiertas por la razón humana.

Para Pico la cábala transmite un conocimiento tanto de las verdades reveladas como de las meramente racionales, por cuanto tanto la magia como la cábala son ciencias sapienciales puestas al servicio de una sabiduría universal y que, por tanto, deben ser compatibles con una fe verdaderamente católica o universal. Se trata de un saber enciclopédico que configura el ejercicio de cualquier forma de saber acerca de lo real, por cuanto establece las condiciones de posibilidad que todo conocimiento debe cumplir, tanto desde un punto de vista teórico como práctico. Por supuesto entre estas condiciones está la aceptación de las verdades reveladas por la Sagrada Escritura, y en este sentido la cábala es la ciencia de los secretos de Dios, pero también de todas las verdades creadas. De ahí que sus verdades deban ser expresadas a través de un lenguaje cosmo-poético o simplemente enciclopédico, que se alcanza mediante la combinación y permutación de las letras del alfabeto. Solo así es posible el desarrollo de un saber o filosofía particular de un ámbito determinado del saber que a su vez debe cumplir la triple «Merkvarah» referido a tres planos internamente jerarquizados, como ahora sucede con la referencia de cualquier verdad a un todo, a un singular y a una palabra capaz de expresar la relación existente entre ambos.

En este contexto la cábala práctica se puede considerar como la parte suprema de la magia natural, por cuanto ninguna acción mágica puede tener eficacia sin una conexión al opus cabalae, que a su vez la hace posible. Ello se debe a la capacidad de la cábala de operar en el plano de lo real y de remitirse a unos niveles de causalidad superior, por cuanto se legitima en nombre de la Sefirat o de una teoría de los nombres divinos y de las inteligencias angélicas. Todo ello presupone una metafísica neoplatónica de carácter jerárquico donde lo inferior depende de lo superior, con sus correspondientes planos epistemológicos y ontológicos, cómo ahora le sucede a la magia respecto de la cábala.

De este modo se atribuye a la cábala una mayor extensión causal que se afirma como una condición de posibilidad de la efectiva realización de la magia. La magia en cambio actúa sobre los planos de la realidad natural menos elevados de las virtudes naturales distribuidas por Dios en el mundo físico con vistas al hombre contemplativo. A este respecto la praxis cabalística actúa en dependencia de la dimensión principal y ejemplar de las virtudes de los agentes sobrenaturales y a un nivel de relaciones estructurales más profundo. De ahí que presuponga la intervención de un intelecto de carácter intuitivo, inmediato e iluminante, al que se asigna una experiencia mística supraintelectiva de carácter angélico. Por eso la cábala se interesa por una causalidad inmediata propia de la causa primera, que a su vez transforma al hombre, mientras que la magia siempre actúa en referencia a las causas segundas y a las virtudes ocultas de los seres naturales. 
Evidentemente la magia y la cábala se necesitan mutuamente, en la media que ambas hacen posible una praxis operativa que permite al hombre actuar conforme a la específica potencialidad concedida por Dios, que encuentra su cumplimiento y fundamento en la sabiduría de la cábala. Solo así el hombre podrá ejercer su libre autodeterminación de un modo conforme a su naturaleza, en la recta dirección de una progresiva elevación contemplativa y práctica en orden al ser a fin de alcanzar una unión mística con Dios mediante el conocimiento del Metatron, por tratarse de una condición de posibilidad del reconocimiento de uno mismo. En cualquier caso la magia y a cábala se necesitan mutuamente, con ayuda del lenguaje en este caso de lenguaje hebraico.

Para justificar estas conclusiones la obra se divide en cinco capítulos:

(1) Nota preliminar a un estudio de la 'magia» de Pico. Se analiza el contexto cultural de la magia en el Renacimiento, deteniéndose especialmente en las propuestas de Pico. Se reconstruye el problema historiográfico del papel desempeñado por sus propuestas de juventud en su posterior desarrollo intelectual.

(2) Instancias y carácter de la magia en Pico. Se propone a modo de hipótesis una interpretación sistemática del significado de la magia en Pico. Se conciben las tesis propuestas en la Oratio como una premisa de los posteriores desarrollos de la Magia theoremata y como un fundamento de las Conclusiones. Se establece la distinción entre la magia lícita y la ilícita en la Oratio. La magia natural como fuente de claridad y gloria. La visión de la magia como un gran milagro para el hombre; imitación de la vida angélica y elevación hasta Dios. El estatuto epistemológico de la magia como ciencia inventiva confirma la divinidad de Cristo. La centralidad cosmológica y antropológica de la 'ratio'. Tipología y ámbitos de la magia: aritmética divina o mágica, la magia basada en la música, la magia astral.

(3) Los orígenes del pensamiento cabalístico. Desde la Qabbalah hebrea a la cábala cristiana. La qabbalah entre la revelación y el lenguaje. Aspectos de la lectura cristológica de la qabbalah.

(4) La teorización de la cábala. Aspectos problemáticos y transfiguración espiritual. Esoterismo sobre el valor sapiencial divino de la cábala. La cábala en la trilogía romana (Oratio, Apología y Conclusiones). Cábala especulativa y cábala práctica.

(5) La teoría de la causalidad:sobre las frases mágicas y la praxis cabalística. Unidad orgánica de la totalidad de lo real y doctrina de la correspondencia. Horizontes de la acción causal: tiempo y eternidad. Praxis mágica y praxis cabalística, entre causalidad mediata e inmediata. Magia, cábala y grados del conocimiento.

Para concluir una reflexión crítica. La magia y el recurso al significado secreto de los números puede parecernos superado en la sociedad contemporánea, pero constituye un universal antropológico que se hace permanentemente presente en todas las culturas. Evidentemente ahora Flavia Buzzetta defiende el carácter cristiano que la cábala tuvo en Pico de la Mirándola, aunque reconoce que no siempre sucede así. Sin embargo no fue Pico de la Mirándola el primero en abordar este tipo de problemas, sino que también lo 
hizo Tomás de Aquino, y otros muchos filósofos de la época, sin llegar en todos los casos a las mismas conclusiones que ahora se proponen. Es más, según Jean Pierre Bach en el prólogo, en este caso se conciben la magia y la cábala como dos formas de oración en el proceso de ascenso hacia la divinización - llegar a ser unus cum Deo spiritus - en un tono claramente desafiante, pero muy abigarrado, frente a los teólogos romanos. Pero a su vez, cómo hemos visto, la cábala se constituye como una condición de posibilidad para la configuración de cualquier tipo de saber, en la medida que permite articular lo singular en su respectiva totalidad con ayuda del lenguaje, ya sea matemático, combinatorio o simplemente alfabético. Sin embargo ahora también se nos advierte de que Pico no llegó a desarrollar un análisis sistemático de estas diversas posibilidades de articulación entre lo singular y la totalidad que ahora ofrece el lenguaje, sea cabalístico o no. Y en este sentido, ¿no habría sido posible tener en cuenta otros posibles desarrollos especulativos menos místicos de este tipo de propuestas, como las formuladas por Sebastián Izquierdo en su Faro de la ciencia (1658), al diferenciar a partir de Tomás de Aquino el tipo de articulación causal que los individuos establecen respecto a Dios, respecto al mundo o respecto a la esencia, sin reducirlas simplemente a algunos resabios cabalísticos presentes en Conte? 